\title{
Acessibilidade do Moodle para surdos: abordagem dos discursos de surdos e ouvintes
}

\author{
Moodle's accessibility for hearing-impaired \\ and hearing users
}

\author{
Carla da Silva FLOR' \\ Daniela Satomi SAITO' \\ Elisa Maria PIVETTA' \\ Vania Ribas ULBRICHT' \\ Tarcisio VANZIN ${ }^{1}$
}

\section{Resumo}

Este artigo trata da acessibilidade da plataforma de educação a distância Modular Object Oriented Distance Learning para usuários surdos. O objetivo da pesquisa foi analisar aspectos ligados à estrutura organizacional, recursos disponíveis e tecnologias de apoio, tendo como suporte o ambiente Modular Object Oriented Distance Learning do Instituto Federal de Santa Catarina. Para tanto, foi realizada uma entrevista semiestruturada com dois grupos distintos: surdos e ouvintes. Por meio do método de análise do Discurso do Sujeito Coletivo, foram identificadas as ideias-chave contidas no discurso dos sujeitos. Tanto surdos como ouvintes indicaram problemas no ambiente, sendo os surdos mais incisivos no que tange ao uso da língua de sinais. Os resultados demonstram que os problemas de acessibilidade estão relacionados tanto ao ambiente em si quanto aos conteúdos nele inseridos.

Palavras-chave: Acessibilidade. Surdez. Moodle.

\section{Abstract}

The aim of this paper is to discuss the accessibility of the Modular Object Oriented Distance Learning e-learning platform for hearing-impaired users. The aim of the research was to analyze the features related to the organizational structure, available resources and supporting technologies, using the Modular Object Oriented Distance Learning platform of the Instituto Federal de Santa Catarina as support. Therefore, a semi-structured interview was conducted with two distinct groups: hearing-impaired and hearing users. The key ideas in the subjects' discourse were identified using the discourse analysis method of the collective subject. Both hearing-impaired and hearing users stated problems in the Moodle platform, but the hearing-impaired users reported problems related to the use of sign language. The results demonstrate that the accessibility problems are both related to the environment itself and content.

Keywords: Accessibility. Deafness. Moodle.

\section{Introdução}

A educação a distância tem trazido vantagens à aprendizagem por permitir maior flexibilidade, inclusão social, atualização de conteúdos, abrangência para um público variado e uso das tecnologias (Ribeiro \& Hirano, 2011). Nesse âmbito, sobressaem-se os Ambientes Virtuais de Ensino Aprendizagem (AVEAS), que se têm

\footnotetext{
1 Universidade Federal de Santa Catarina, Departamento de Engenharia do Conhecimento, Programa de Pós-Graduação em Engenharia e Gestão do Conhecimento. Campus Universitário Reitor João David Ferreira Lima, Trindade, 88040-900, Florianópolis, SC, Brasil. Correspondência para/Correspondence to: C.S. FLOR. E-mail: <carla.flor@gmail.com>.

Recebido em 6/1/2014, reapresentado em 20/5/2014 e aceito para publicação em 11/6/2014.
} 
mostrado promissores no objetivo de promover o acesso à educação. Esses ambientes têm como alicerce a internet e atualmente estão disponíveis em diversas plataformas educacionais (Gabardo et al., 2010).

O estudo comparativo realizado por Gabardo et al. (2010) sobre as oito plataformas virtuais de ensino aprendizagem mais citadas nas fontes de pesquisa demonstrou que há uma disparidade entre as necessidades pedagógicas e as tecnológicas que as impede de oferecer os recursos necessários à educação a distância, sobretudo em relação à acessibilidade. A pesquisa incluiu o ambiente virtual Modular Object Oriented Distance Learning (Moodle), que é uma plataforma bastante difundida em todo o mundo, estando presente em 232 países, inclusive no Brasil. O Moodle possui atualmente 68322947 usuários em 79404 sites registrados (Estatísticas..., 2013).

O quesito acessibilidade pesquisado no estudo citado revelou que o ambiente Moodle possibilita a utilização de leitores de tela, o que atende de forma peculiar o deficiente visual, mas precisa ser aprimorado para verificar se atende também as necessidades dos usuários surdos, assegurados pelo Decreto ㄲo 5.626 (Brasil, 2005), que regulamenta o acesso à educação em instituições de ensino no país. De acordo com o decreto, considera-se surdo o sujeito que compreende e interage com o mundo por meio de experiências visuais, e, em virtude dessa característica, manifesta sua cultura principalmente pelo uso da Língua Brasileira de Sinais (Libras) (Brasil, 2005).

No intuito de verificar a experiência do surdo no ambiente Moodle, foi realizada uma pesquisa semiestruturada a fim de saber se a estrutura organizacional, os recursos utilizados e as tecnologias de apoio atendem suas necessidades. Esta pesquisa foi realizada com surdos e ouvintes, com o objetivo de comparar as divergências entre ambos os discursos. O método de análise utilizado foi o Discurso do Sujeito Coletivo (DSC) e o ambiente virtual do Instituto Federal de Santa Catarina (IFSC), que utiliza a plataforma Moodle, foi usado como apoio. A seguir são detalhados os aspectos metodológicos, os resultados, a discussão e, por fim, as considerações finais.

\section{Procedimentos metodológicos}

A abordagem metodológica deste artigo é de cunho qualitativo e exploratório, e objetiva esclarecer como o ambiente virtual Moodle é qualificado quanto à acessibilidade para o surdo do ponto de vista dos usuários surdo e ouvinte. Foram analisados aspectos como a estrutura organizacional, os recursos disponíveis e as tecnologias de apoio. Também foram consideradas as opiniões dos pesquisados quanto à maneira como são tratados os conteúdos, tendo como base o ambiente Moodle do IFSC.

O tipo de coleta utilizado foi a entrevista semiestruturada, uma vez que, de acordo com Matallo e Pádua (2009), as entrevistas são pesquisas que podem ser aplicadas a qualquer segmento da população, inclusive a pessoas que não dominam a língua escrita, como pode ser o caso dos usuários surdos. De acordo com Flor et al. (2013), a surdez não impede apenas que o surdo pronuncie e escute a língua oral, mas também que entenda a estrutura fonética dos sons, que é utilizada na estruturação sintática das palavras escritas. Para esse público, as entrevistas foram realizadas diretamente em língua de sinais, visando a uma comunicação livre de barreiras. Segundo Bordieu (1998), na medida do possível, é importante que o pesquisador fale a mesma linguagem do pesquisado, deixando seu capital cultural para que ambos possam se entender. Além do mais, as entrevistas são uma técnica eficiente quando o que se quer é obter dados do comportamento humano, que, no caso desta pesquisa, trata da visão do indivíduo perante a interação com o ambiente do Moodle.

Nas entrevistas semiestruturadas são formuladas previamente algumas perguntas de pesquisa sobre o que está sendo estudado, possibilitando, ou até incentivando, que o pesquisado fale livremente sobre o tema à medida que novos desdobramentos do assunto principal começam a emergir (Matallo \& Pádua, 2009). Nesta pesquisa, foram utilizadas quatro perguntas principais (Quadro 1), acrescidas de perguntas secundárias que surgiam a partir das respostas dos participantes.

A partir da definição das perguntas de pesquisa, o próximo passo foi a escolha dos sujeitos constituintes da pesquisa e o devido dimensionamento. Para o presente estudo, foram selecionados dois grupos: o primeiro 
constituído por surdos e o segundo por ouvintes. A seleção de grupos com perfis distintos visa à análise dos discursos de cada perfil e à identificação das divergências entre ambos na avaliação do AVEA e das questões de acessibilidade relacionadas ao tema de pesquisa proposto.

O primeiro grupo (Quadro 2) foi constituído por três surdos com boa relação com a língua portuguesa na modalidade escrita e com o uso das novas tecnologias, atuando profissionalmente como professores. O olhar desses indivíduos traz, além do ponto de vista do sujeito surdo, a experiência e os conhecimentos de profissionais envolvidos com a educação de surdos.

O segundo grupo (Quadro 3) foi constituído por três ouvintes, com boa relação com o uso das tecnologias.

Em relação à análise dos dados, foi utilizado o DSC, que é uma forma de apresentação dos resultados utili- zada em pesquisas qualitativas. O DSC reúne depoimentos como fonte de dados expressos em primeira pessoa do singular, o que imprime o sentimento de uma coletividade, que é quem faz emitir o discurso (Lefèvre et al., 2003). As técnicas utilizadas nesta pesquisa estão detalhadas a seguir.

\section{Resultados}

Finalizada a etapa de coleta de dados, realizada em 2012, as entrevistas foram devidamente transcritas e documentadas para a análise dos dados, utilizando o método de análise do Discurso do Sujeito Coletivo. De acordo com Lefèvre F. e Lefèvre A.M.C (2006), o método busca identificar as questões de autoexpressão, mas também as opiniões coletivas.

O Discurso do Sujeito Coletivo é, por isso, uma proposta explícita de reconstituição de um ser

Quadro 1. Perguntas utilizadas na pesquisa semiestruturada.

\footnotetext{
1. Tendo como base a sua experiência com o Moodle, como o surdo avalia suas necessidades para a compreensão dos conteúdos das aulas no ambiente?

2. Que tipo de recursos colaborariam mais para a compreensão dos conteúdos? Considere os recursos de comunicação e interação existentes ou ideias que gostaria que fossem implementadas no Moodle.

3. O que dificulta a compreensão da estrutura organizacional do Moodle?

4. Quais tecnologias de apoio você considera importantes para auxiliar o aprendizado e a compreensão dos conteúdos pela pessoa surda?
}

Fonte: Elaborado pelos autores (2013).

Quadro 2. Perfil dos surdos entrevistados.

\begin{tabular}{llll}
\hline Características & Sujeito 1 & Sujeito 2 & Sujeito 3 \\
\hline Sexo & Feminino & Masculino & Masculino \\
Profissão & Professor & Professor & Professor \\
Formação & Doutoranda & Mestre & Especialista \\
\hline
\end{tabular}

Fonte: Elaborado pelos autores (2013).

Quadro 3. Perfil dos ouvintes entrevistados.

\begin{tabular}{llll}
\hline Características & Sujeito 4 & Sujeito 5 & Sujeito 6 \\
\hline Sexo & Feminino & Feminino & Masculino \\
Profissão & Estudante & Designer & Militar \\
Formação & Graduanda & Doutoranda & Especialista \\
\hline
\end{tabular}

Fonte: Elaborado pelos autores (2013). 
ou entidade empírica coletiva, opinante na forma de um sujeito de discurso emitido na primeira pessoa do singular. [...] Um sujeito coletivo, no DSC, vem se constituindo numa tentativa de reconstituir um sujeito coletivo que, enquanto pessoa coletiva, esteja, ao mesmo tempo, falando como se fosse indivíduo, isto é, como um sujeito de discurso "natural", mas veiculando uma representação com conteúdo ampliado (Lefèvre F. \& Lefèvre A.M.C., 2006, p.519).

Os dados qualitativos desta pesquisa foram obtidos após a seleção das Expressões-Chave (ECH) e da identificação das Ideias Centrais (IC) dos extratos das respostas às perguntas contidas no Quadro 1. Em cada uma das perguntas foi obtido um discurso para cada perfil de usuários (surdos e ouvintes), de modo a possibilitar a comparação entre as diferenças existentes entre a percepção do usuário surdo e do ouvinte quanto à utilização pelo surdo do ambiente Moodle e seus conteúdos educacionais.

Em relação à pergunta um "Tendo como base a sua experiência com o Moodle, como o surdo avalia suas necessidades para a compreensão dos conteúdos das aulas no ambiente?", os usuários surdos demonstraram preocupação com o uso excessivo de texto no ambiente e pouca utilização da Libras:

A maioria dos professores coloca muitos textos longos, sem Libras, e isto é cansativo. Os conteúdos precisam ser mais visuais. A melhor forma de trabalhar o conteúdo para o surdo seria ter o texto e seu equivalente em Libras para que o aluno possa comparar os dois conteúdos.

O grupo de usuários ouvintes ao responder à mesma pergunta demonstrou um discurso menos uniforme, também preocupado com o uso excessivo do texto, porém focado em outras questões do ambiente, como a linguagem gráfica, uso de imagem e interatividade:

Depende das atividades que o professor coloca, se ele colocar muito texto vai dificultar para o surdo. Não é só por causa do surdo, mas não é chamativo, não dá vontade de clicar nas coisas... faltou uma imagem, uma explicação melhor, tem que ser mais interativo. Uma pessoa que tenha problemas auditivos deve compreender a linguagem gráfica utilizada. Por outro lado, talvez o acesso a essas ferramentas interativas possa causar algum impacto ou desânimo em um usuário que tenha esse tipo de deficiência.
Na pergunta dois "Que tipo de recursos colaborariam mais para a compreensão dos conteúdos (pelo surdo)? Considere os recursos de comunicação e interação existentes ou ideias que gostaria que fossem implementadas no Moodle", os surdos enfatizaram o uso da Libras, principalmente nas ferramentas e atividades, como a videoconferência. Também demonstraram dificuldade em acompanhar a atividade de chat em texto:

Os conteúdos das aulas deveriam ser mais em vídeo e conter tradução e interpretação para ajuda. Ainda não temos muito conteúdo em Libras. A animação poderia ajudar a explicar os conteúdos das aulas, os conceitos. Os fóruns de discussão deveriam ter a possibilidade de postagem de vídeo. A videoconferência é muito melhor para o surdo do que ochat, nela dá pra usar Libras, já o chat só em texto éruim, é difícil de acompanhar.

Os ouvintes também responderam à pergunta dois focando o uso de recursos visuais e Libras, mas apresentaram um discurso menos uniforme. Um dos sujeitos ouvintes expressou que o deficiente auditivo que já passou por algum grau de instrução não terá grandes dificuldades em acessar o ambiente, referindo-se ao uso de chats e recursos interativos, enquanto os demais respondentes demonstraram preocupação com o uso do chat e de uma linguagem mais direcionada para o surdo:

O vídeo é uma das coisas mais importante para atividades online, ainda mais para surdos que podem usar Libras, podem fazer vídeos em Libras ou escrita em Libras. Ele tem que usar aulas mais visuais, recursos, talvez power points, e mais vídeos, mas lógico que daí o vídeo vai ter que ter uma legenda. No caso do chat, é ruim para os surdos, porque é muito rápido para eles lerem tudo, para eles interpretarem. [...] E as que não são instantâneas eles preferem. No entanto, um deficiente auditivo que já tenha passado por uma instrução, saiba se relacionar com o mundo atual, saiba ler e escrever, se comunicar de um modo que não seja o modo auditivo, provavelmente isso será bem utilizado.

A pergunta três "O que dificulta a compreensão da estrutura organizacional do Moodle?" resultou em respostas sucintas, que, no caso dos usuários surdos, evidenciaram uma confusão na organização do ambiente: 
Do jeito que o Moodleéorganizado dificulta muito a localização de informações e conteúdos. Essa estrutura de tópicos não é muito clara, as páginas são muito longas, compridas [...] Está tudo muito confuso.

Já em relação aos usuários ouvintes, o grupo se dividiu entre aqueles que concordaram que a estrutura organizacional estivesse de bom nível e aquele que discordou e demonstrou dificuldades em encontrar determinadas coisas. O discurso foi elaborado com extratos que se contrariam:

[...] pela simplicidade, eu acredito esteja de bom nível, mas acho que não está fácil de encontrar as coisas. Complica. Não tem uma coisa rápida.

Quanto à pergunta quatro "Quais tecnologias de apoio que você considera importantes para auxiliar o aprendizado e a compreensão dos conteúdos pela pessoa surda?" , os surdos demonstraram grande aceitação dos glossários em língua de sinais, enquanto os tradutores automáticos português-libras foram menos aceitos por conta da tecnologia atual não atender às necessidades dos surdos:

O Glossário é importante para apresentar sinais que são combinados em sala de aula e explicar outros novos não conhecidos pelos alunos. Os tradutores precisam sermelhorados antes de serem colocados nos ambientes, pois apresentam movimentos meio quebrados.

O relato dos usuários ouvintes, por sua vez, evidenciou a necessidade da disponibilização de um dicionário libras-português/português-libras, de um tradutor automático português-libras e da inserção de legendas e traduções para libras em vídeos, o que demostra certa divergência dos surdos, que preferem tradutores humanos:

Seria legal se tivesse um dicionário libras-português, português-libras. Tem que ter as traduções aqui... Não tem nem legenda, nem tradução para libras. Um tradutor [automático] pode ajudar.

\section{Discussão}

Em todas as perguntas, os surdos apresentaram um discurso bastante homogêneo quanto às dificuldades e às demandas em um ambiente virtual de aprendizagem, o que marca a dificuldade em relação a con- teúdos puramente textuais. As entrevistas destacaram também a necessidade de conteúdos em vídeo, preferencialmente em Libras, bem como de implementação de ferramentas de interação síncronas e assíncronas que possibilitem seu uso. Corroborando esse posicionamento, os discursos evidenciaram a rejeição do uso de ferramentas como as de chat pela abordagem textual e dificuldade que apresentam em relação ao acompanhamento do fluxo da informação. Os chats são frequentes em redes sociais, todavia demonstraram-se dificultosos para os surdos, que preferem videoconferências por possibilitarem o uso da Libras.

Dessa forma, além de trazerem à tona aspectos sobre as modalidades de comunicação do sujeito surdo, também evidenciaram o movimento da comunidade surda em prol do fortalecimento do status da Libras como uma língua, conforme preconiza o Decreto № 5.626 (Brasil, 2005), que regulamenta o uso da Libras nas instituições de ensino no país. Não só nos ambientes virtuais de aprendizagem, mas também em outras modalidades de redes sociais e sistemas, a língua de sinais deve ser inserida, sendo ela um dos requisitos para um Design Universal.

As abordagens de inserção da língua de sinais podem adotar uma perspectiva que privilegia o uso da língua de sinais na forma de vídeos inseridos diretamente na interface ou que apresentem os conteúdos na modalidade escrita e com a possibilidade de abrir o vídeo correspondente em língua de sinais em outra camada ou janela. Assim, é necessário que sejam realizados estudos quanto à efetividade/impacto do uso dessas abordagens no que diz respeito à navegabilidade e à apreensão dos conteúdos em um ambiente digital.

No que tange à organização do ambiente, os discursos dos surdos mostraram que eles sentiram mais dificuldades do que os ouvintes supunham que eles teriam (três surdos consideraram o Moodle confuso, enquanto apenas um ouvinte não aprovou a organização do ambiente). A qualificação por parte dos surdos foi pior do que por parte dos ouvintes. Tanto o Moodle como outros sistemas de informação, tais como blogs, tutoriais de software (a exemplo dos manuais de ajuda dos softwares), fóruns de discussão, entre outros, apresentam estruturas de tópicos ou âncoras que dificultam a navegação dos surdos. Normalmente, esse tipo de estrutura 
apresenta uma grande quantidade de informação textual em uma mesma página, o que torna a leitura ainda mais complexa para o surdo. Essa dificuldade com a leitura de textos longos, evidenciada no discurso dos surdos, reforça a tese, apresentada por Flor et al. (2013), de que a compreensão dos textos escritos para os surdos fica prejudicada.

As entrevistas com os sujeitos ouvintes permitiram o acesso à variedade de visões que as pessoas ouvintes têm do sujeito surdo. Os discursos foram heterogêneos, o que dificultou a construção do sujeito coletivo proposto por Lefèvre F. e Lefèvre A.M.C (2006). O discurso dos ouvintes não manteve a uniformidade detectada no grupo dos sujeitos surdos (das quatro perguntas feitas aos ouvintes, apenas a última não apresentou expressões que se contrariam, enquanto os surdos não expressaram opiniões contrárias para um mesmo aspecto abordado). Alguns ouvintes indicaram conhecimento e preocupação com as diferenças dos surdos, apresentaram discurso consonante com o discurso dos surdos e recomendaram a melhoria do ambiente virtual. No entanto, outros refletiram o desconhecimento das dificuldades enfrentadas por esse público em virtude da sua modalidade de comunicação e fizeram avaliação positiva do projeto gráfico do AVEA, demonstrando não compreender as barreiras de aprendizagem da língua portuguesa enfrentadas pela maioria da comunidade surda. Em relação às ferramentas de apoio, o grupo dirigiu suas atenções ao uso de ferramentas automáticas de tradução e à inclusão de legendas, o que contrasta com as respostas dos surdos que consideraram as ferramentas de traduções atuais como imaturas e demonstraram a necessidade por glossários terminológicos nos ambientes de aprendizagem.

\section{2}

\section{Conclusão}

Os discursos dos surdos e ouvintes, para cada pergunta, foram construídos tendo como base os extratos em primeira pessoa obtidos com o DSC, uma vez que essa técnica de pesquisa preconiza o uso da junção dos discursos individuais para representar a coletividade. Os dados revelados por meio do DSC são relevantes ao apresentar as classes de recursos que possuem impacto direto na acessibilidade do Moodle sob o ponto de vista de surdos e ouvintes, identificando expressão da coletividade nos discursos individuais. Essas classes de recursos podem ser aplicadas a qualquer sistema vinculado à Ciência da Informação, como fóruns de discussão, ambientes informacionais, bibliotecas virtuais etc. Algumas necessidades e discussões, no entanto, poderão ser aprofundadas de acordo com a peculiaridade de cada sistema, como a busca em Libras nos repositórios digitais, os livros em Libras nas bibliotecas virtuais e a captura de vídeos em Libras e reconhecimento de gestos para tradução e postagem em fóruns.

Tanto surdos quanto ouvintes apresentaram um conjunto de questões em relação ao uso do ambiente Moodle. Aspectos relativos à organização e à navegação do ambiente foram discutidos tanto por surdos como por ouvintes, indicando a necessidade de melhoria do projeto de interface do ambiente virtual. Por se tratar de uma plataforma aberta, é possível que a própria instituição utilizadora realize as devidas adequações à estrutura padrão. As alterações no ambiente, no entanto, podem ser aplicadas a qualquer outro sistema de informação.

O grupo dos surdos apresentou um discurso bastante homogêneo quanto às demandas em relação ao AVEA, pontuando elementos que devem ser explorados e marcando fortemente suas reivindicações por recursos mais visuais e conteúdos em Língua de Sinais. Os ouvintes, por sua vez, além de relatarem problemas quanto ao uso excessivo de textos, colocaram como ponto relevante a disponibilização de tradutores automáticos no ambiente. O que ficou evidenciado nesta pesquisa foi a necessidade de conteúdos multimídias como animações e vídeos, sobretudo em Libras, e textos curtos, ao contrário das páginas excessivamente longas, que, mesmo que organizadas por meio de tópicos ou âncoras, ficam complexas para os surdos. Essas assertivas valem tanto para AVEA quanto para bibliotecas digitais, sites de museus ou outros sistemas de informação.

As questões reveladas nos discursos coletivos mostraram que a acessibilidade para os surdos não está apenas no contexto da estrutura e do ambiente virtual, que é classificado como puramente textual. Parte dos resultados está relacionada aos conteúdos e materiais disponibilizados no Moodle, o que demonstra que, para um ambiente efetivamente acessível, é necessário que 
haja a convergência de esforços de programadores, professores e desenvolvedores de conteúdo. Assim como em uma biblioteca virtual os livros devem estar traduzidos para Libras, também no Moodle os conteúdos - como arquivos dos tipos PDF, Power Point e Documentos de texto-, devem possibilitar a leitura em língua de sinais.

Para que os esforços dos profissionais sejam efetivos, é importante que as estratégias e os conteúdos utilizados sejam orientados às características e às necessidades dos surdos. Sendo assim, é importante que os profissionais envolvidos compreendam as diferenças que os surdos apresentam em relação a suas formas de interação com o entorno e o reflexo destas sobre a aprendizagem. Sem tal compreensão, a tendência é que os profissionais ouvintes continuem a desenvolver conteúdos fundamentados em sua cultura e percepção da realidade, recaindo em problemas já identificados nesta pesquisa. Muitas vezes os sistemas de informação apresentam tradução em Libras de apenas parte do conteúdo, geralmente do que é fixo nas páginas, ou seja, do que não é atualizado constantemente, devido aos altos custos para manter um site atualizado em ambas as línguas (português/Libras) por tradutores humanos. Nesse sentido, os assistentes virtuais, como os tradutores automatizados, deveriam ser aprimorados e posteriormente testados para validar junto aos surdos e aos ouvintes o

\section{Referências}

Brasil. Presidência da República. Decreto no 5.626, de 22 de dezembro de 2005. Regulamenta a Lei n 10.436, de 24 de abril de 2002, que dispõe sobre a Língua Brasileira de Sinais Libras, e o art. 18 da Lei n 10.098, de 19 de dezembro de 2000. Diário Oficial da União, Brasília, DF, 23 dez. 2005. Disponível em: <http://www.planalto.gov.br/ccivil_03/_ato2004-2006/ 2005/decreto/ d5626.htm>. Acesso em: 12 dez. 2013.

Bordieu, P. O poder simbólico. 2.ed. Rio de Janeiro: Bertrand, 1998.

Estatísticas. Modular Object Oriented Distance Learning. 2013. Available from: <https://moodle.net/stats/>. Cited Apr 19, 2013.

Flor, C.S.; Vanzin, T.; Ulbricht, V.R.; Recomendações da WCAG 2.0 (2008) e a acessibilidade de surdos em conteúdos da web. Revista Brasileira de Educação Especial, v.19, n.2, p.161-168, 2013.

Gabardo, P. et al. Estudo comparativo das plataformas de ensino-aprendizagem. Encontros Bibli: Revista Eletrônica de benefício da inserção dessa tecnologia em ambientes dinâmicos. Os comentários dos surdos indicam a forte rejeição do público quanto aos tradutores automatizados. Boa parte da rejeição identificada se dá em virtude da imaturidade das pesquisas relacionadas à língua de sinais, que ainda são bastante recentes. Atualmente, os assistentes virtuais realizam a tradução para uma estrutura de português sinalizado, que é diferente da estrutura gramatical da Libras. Some-se a isso o fato de os bancos de dados não possuírem unidades lexicais suficientes para uma tradução, resultando em uso excessivo de recursos de datilologia.

Por fim, áreas de pesquisa relacionadas à visualização da informação e arquitetura da informação se mostram como campos férteis para explorar novas estratégias para apresentação dos conteúdos, sendo elas relevantes e benéficas não somente para os surdos como também ao público ouvinte.

\section{Agradecimentos}

À Coordenação de Aperfeiçoamento de Pessoal de Nível Superior pelo financiamento do Projeto AUX-PE-PROESP1020/2009 e ao Conselho Nacional de Desenvolvimento Científico e Tecnológico pelo financiamento do Projeto $n^{\circ}$ 458710/2013-0.
Biblioteconomia e Ciência da Informação, n. (Especial), 2010. Disponível em: <https://periodicos.ufsc.br/index.php/eb/ article/view/1518-2924.2010v15nesp2p65>. Acesso em: 12 dez. 2013.

Lefèvre, F. et al. A utilização da metododologia do discurso do sujeito coletivo na avaliação qualitativa dos cursos de especialização Capacitação e Desenvolvimento de Recursos Humanos em Saúde - CADRHU. Saúde e Sociedade, v.12, n.2, p.68-75, 2003.

Lefèvre, F.; Lefèvre, A.M.C. O sujeito coletivo que fala. Interface: Comunicação, Saúde, Educação, v.10, n.20, p.517-524, 2006.

Matallo, E.; Pádua, M. Metodologia da pesquisa: abordagem teórico-prática. 15.ed. Campinas: Papirus, 2009.

Ribeiro, C.F.; Hirano, F.W.P. Educação a distância. Revista Científica da AJES, v.2, n.5, p.1-19, 2011. Disponível em: <http:// www.revista.ajes.edu.br/arquivos/artigo_2011090716 0632.pdf>. Acesso em: 12 dez. 2013. 

